\title{
FINAL PROJECT REPORT
}

Project Title: An Improved Method of Manufacturing Corrugated Boxes: Lateral Corrugator

Date of Report: December 10, 2008

Recipient: Georgia Tech Research Corporation

Performing Organization: Institute of Paper Science and Technology at Georgia Tech $50010^{\text {th }} \mathrm{St}, \mathrm{NW}$

Atlanta, GA 30332-0620

Award Number: DE-FC36-01G010616

Subcontractors: None

Other Partners: Temple-Inland Paperboard and Packaging, Smurfit-Stone Container Corp., MarquipWardUnited, Corrugated Gear, Albany International, Armstrong, Container Graphics Corporation, CUE, Harper-Love Adhesives, The Johnson Corporation, Corn Products International, Hardy Instrumentation, WIKA Instrument Corp., Chicago Electric, Pamarco Global Graphics, Bill Nikkel

Contacts: $\quad$ Michael Schaepe, Principal Investigator (formerly with IPST at Ga Tech) 678-571-9687 (mobile phone)

Frank Murray, Principal Research Engineer 404-894-9592

frank.murray@ipst.gatech.edu

Roman Popil, Senior Research Scientist

404-894-9722

roman.popil@ipst.gatech.edu

Project Team: Gibson Asuquo, gibson.asuquo@go.doe.gov

Tim Ramsey, tim.ramsey@go.doe.gov

Beth Dwyer, beth.dwyer@go.doe.gov

Project Objective: The goal of this project is to develop and demonstrate a commercially viable lateral corrugating process. This includes designing and building a pilot lateral corrugator, testing and evaluating the pilot machine, and developing a strategy for commercialization. 
Document Availability: Reports are available free via the U. S. Department of Energy (DOE) Information Bridge: Web Site http://www.osti.gov/bridge

Reports are available to DOE employees, DOE contractors, Energy Technology Data Exchange (ETDE) representatives, and Informational Nuclear Information System (INIS) representatives from the following source:

Office of Scientific and Technical Information

P.O. Box 62

Oak Ridge, TN 37831

Tel: (865) 576-8401

Fax: (865) 576-5728

E-mail: reports@osti.gov

Web Site: http://www.osti.gov/contact.html

Acknowledgment: This report is based upon work supported by the U. S.

Department of Energy under Award No. DE-FC36-01G010616

Disclaimer: "Any findings, opinions, and conclusions or recommendations expressed in this report are those of the author(s) and do not necessarily reflect the views of the Department of Energy"

Proprietary Data Notice: If there is any patentable material or protected data in the report, the recipient, consistent with the data protection provisions of the award, must mark the appropriate block in Section K of the DOE F 241.3, clearly specify it here, and identify them on appropriate pages of the report. Other than patentable material or protected data, reports must not contain any proprietary data (limited rights data), classified information, information subject to export control classification, or other information not subject to release. Protected data is specific technical data, first produced in the performance of the award, which is protected from public release for a period of time by the terms of the award agreement. Reports delivered without such notice may be deemed to have been furnished with unlimited rights, and the Government assumes no liability for the disclosure, reproduction or use of such reports. 


\section{Table of Contents}

- Executive Summary

Page 4

- Project Background

Page 5

- Project Completion / Status

Page 9

- Test Results and Cost

Page 9

- Savings Dimensional Estimates

Page 11

- Publications / Milestones Status

Page 12

\section{List of Figures and Tables}

Figure 1 Graphical benefit of lateral vs. conventional box construction on box compression strength

Page 6

Figure 2 Graphical benefit of various partial and full lateral construction designs

Page 6

Figure 3 Schematic of corrugator machine concept to produce full lateral box construction

Page 7

Figure 4 Photo of new corrugating stack for the pilot lateral corrugator

Page 8

Figure 5 Photo of box crush test specimen from the DOE demonstration (July 1, 2008)

Page 10

Table1 Box crush test and deflation (bending stiffness) test results from partial and full lateral boxes from the DOE demonstration

Page 10 (July 1, 2008) 


\section{Executive Summary:}

Paper physicists have understood for some time that a corrugated box constructed from outer liner sheets having a predominant fiber orientation aligned with the corrugating flute direction would posses higher stiffness and crush resistance (per unit of fiber weight) than the conventional box construction, where the liners' fiber orientation is aligned at a right angle to the flute direction. Such increased performance per unit of fiber weight could result in fiber reduction and energy savings for boxes having equivalent performance specifications.

The goal of this project was to develop and demonstrate a commercially viable lateral corrugating process. This included designing and building a pilot lateral corrugator, testing and evaluating pilot machine made boxes, and developing a strategy for commercialization.

The machine was constructed, de-bugged, and operated (DOE demonstration July 1, 2008) to produce corrugated sheets (blanks) having one liner rotated (Partial) and both liners rotated (Full Lateral). These blanks were made into boxes for crush (BCT) and stiffness (Deflection) testing. Results from these test show comparable performance improvements (per unit of fiber weight) as has been seen from manually constructed sample boxes.

The dimensional estimation of the cost savings value associated with a wholesale shift of US liner board (kraft liner, test liner, and recycle liner) and corrugated box production is estimated to be up to one billion USD per year (using a $15 \%$ basis weight reduction on total US production of thirty million tons of liner, and estimating liner variable production cost at \$250 per ton). 


\section{Background:}

Since paper is non-isotropic and fibers tend to orient in the machine direction, machine direction (MD) compressive strength of paper exceeds that of the cross-machine direction (CD). In a conventional corrugator, the paper machine direction is perpendicular to the flute direction. Therefore, a typical corrugated container does not take advantage of the stronger compressive strength of the paper machine direction.

Experiments conducted at IPST on manually constructed boxes demonstrated that combined corrugated board construction with both linerboards' MD orientation rotated to be in the transverse direction of the combined-board, generated box compression strength improvements of up to $30 \%$ over conventionally oriented board constructions (fig. 1). Yet, with the corrugated medium MD orientated conventionally, flat crush, handling toughness, and board rigidity were maintained. It was found that a box utilizing $15 \%$ lighter materials with the linerboard transversely oriented generated comparable stacking strength to a conventional box.

A further test using a manually spliced roll of liner (sections rotated ninety degrees) was completed to demonstrate that a pilot machine made corrugated structure would exhibit the same strength and stiffness benefits. Lateral corrugating was performed using the IPST pilot corrugator where full width roll lengths of commercial linerboard were sequentially manually butt spliced together and rewound into a roll. This spliced linerboard roll was run through the single facer with its MD perpendicular to the direction of corrugating and combined with medium having the usual orientation of MD being in the direction of corrugating. A series of test boxes were made of type C-flute with $205 \mathrm{~g} / \mathrm{m}^{2}$ linerboards oriented regularly and with lateral corrugating oriented linerboards (designated as "CD-MD-CD Lateral"), the medium chosen was of $127 \mathrm{~g} / \mathrm{m}^{2}$ and remained regularly oriented. Linear corrugated boards (dubbed "MD-MD-MD") were also prepared similarly as the lateral boards with the addition of the medium corrugating roll also consisting of a series manually spliced sections of medium rotated 90 degrees such that the medium ran through the single facer along its CD resulting in flutes parallel to the MD. Lateral corrugating increased the box crush (BCT) of test boxes by $26 \%$ compared to regularly oriented test boxes (dubbed "Run 2 Green" in Fig. 2) which summarizes the BCT of the series of test boxes all made of the same components and orientations as designated. The results are consistent with those observed from manually made corrugated sheets. 


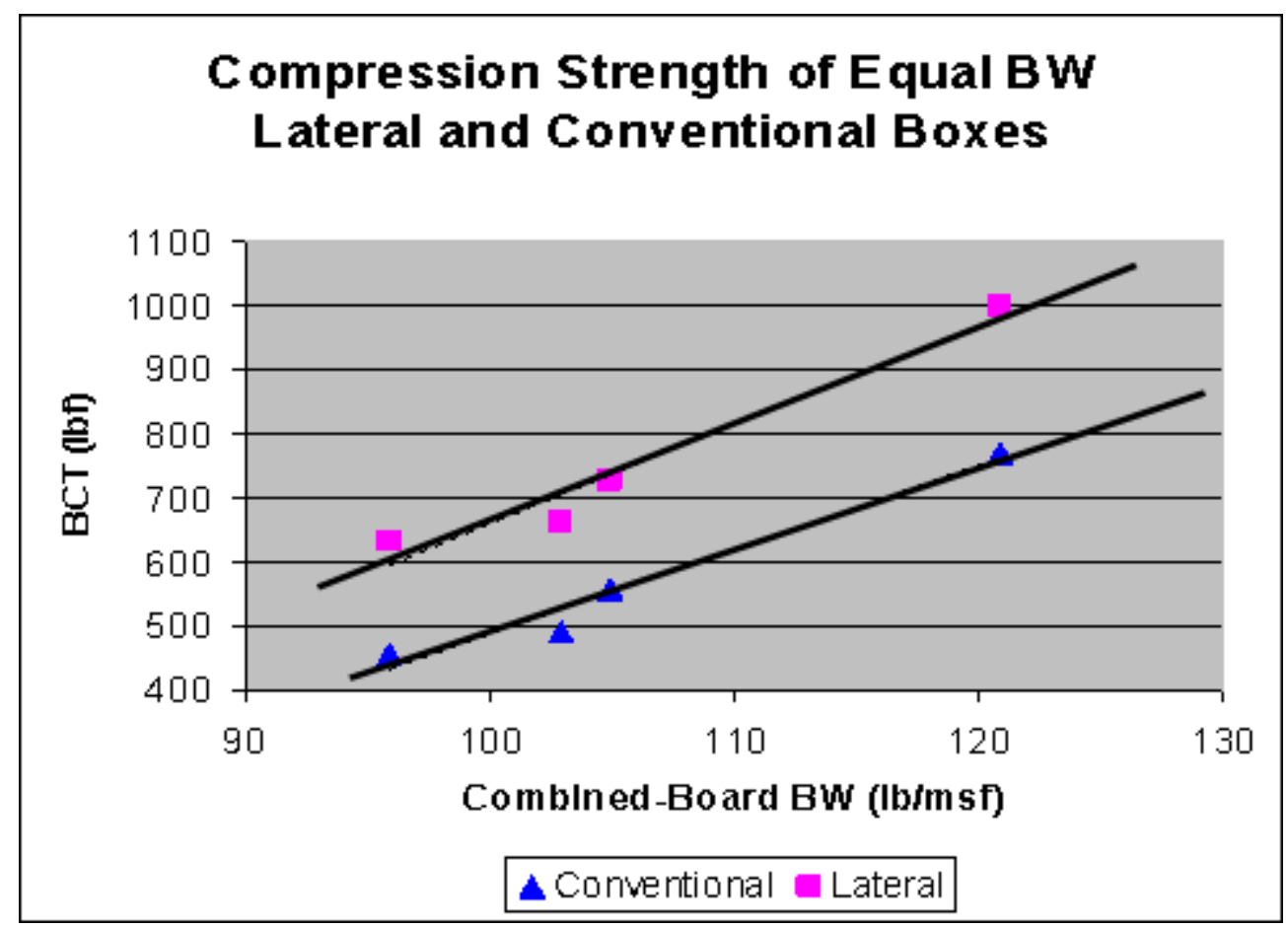

Fig. 1 Compression Strength Improvement due to Lateral Corrugation

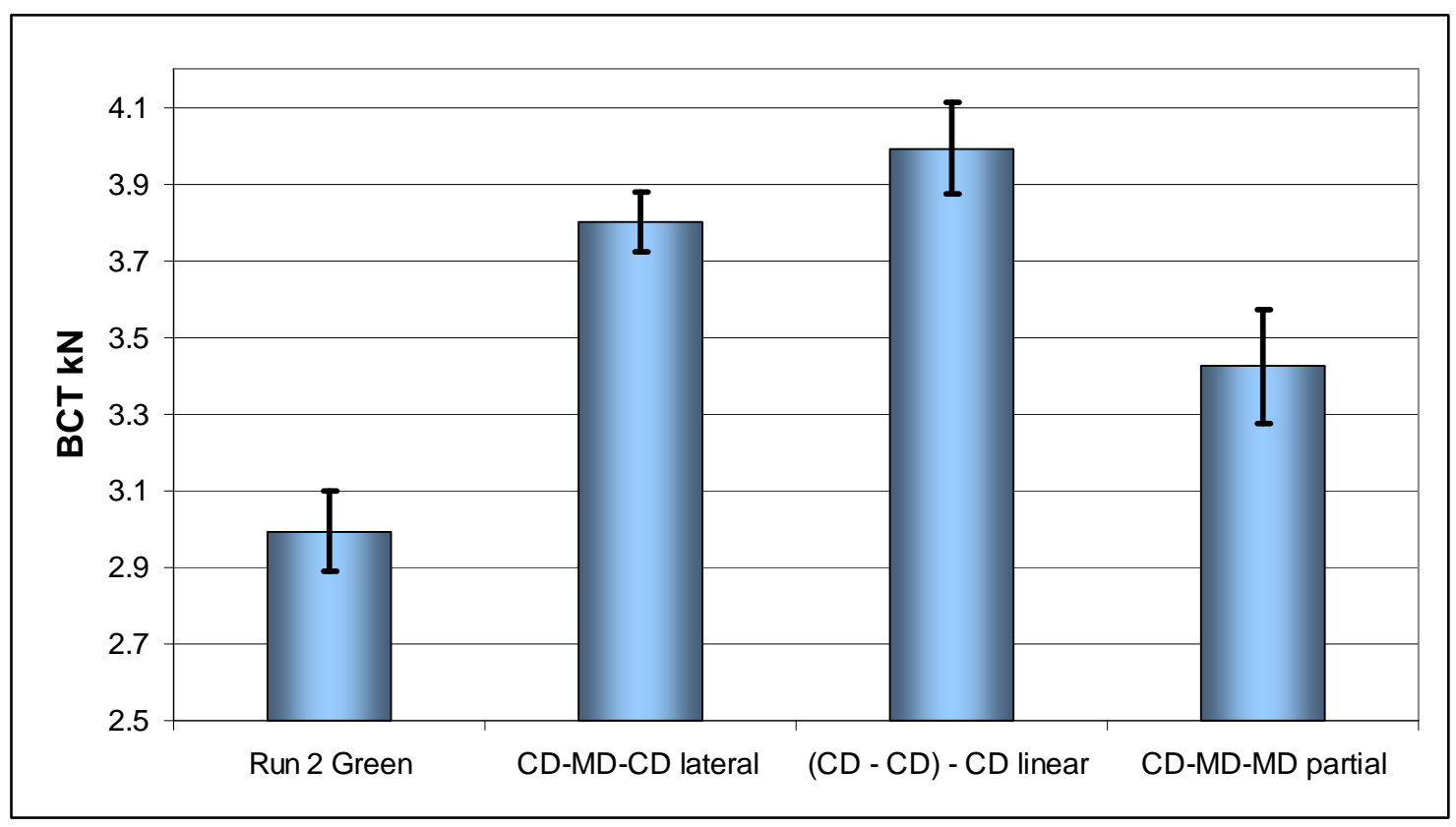

Fig. 2 BCT Summary of boxes from various constructed board blank orientation 


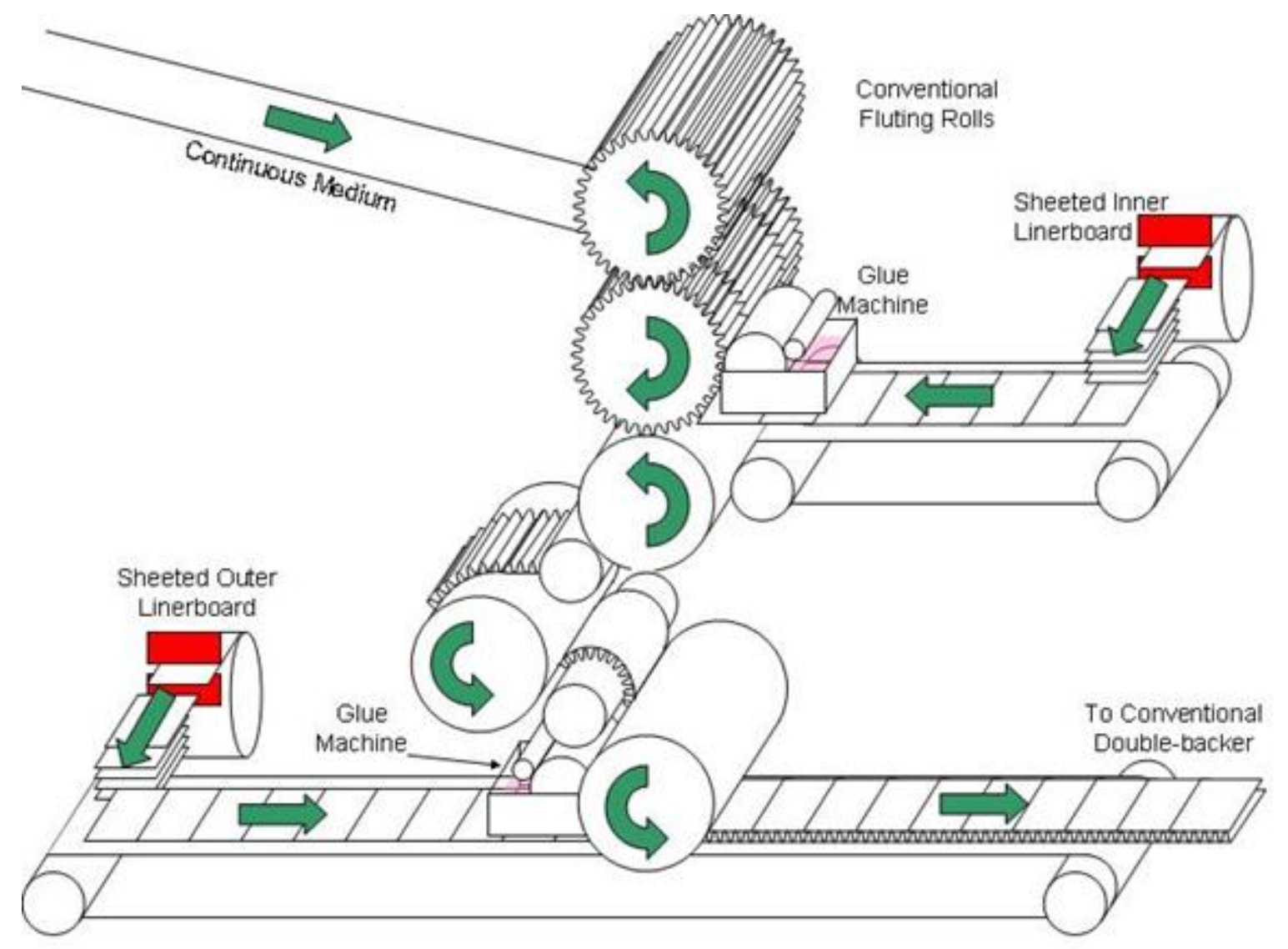

Fig. 3 Schematic of machine concept to produce lateral Corrugation

A method to produce combined-board with the linerboard oriented in the transverse direction has been considered (Fig. 3). This method of box manufacturing could reduce fiber consumption (lighter liner) $15 \%$ and improve the compressive strength to weight ratio of corrugated shipping containers considerably, thereby significantly reducing manufacturing fiber and energy usage. The technology to produce such a combined-board would involve conventional fluting of the medium. The transverse orientation of the linerboard(s) would be achieved through a sheeting operation. Single-facing and double-backing would utilize conventional, but state-of-the-art corrugating technologies.

This project has been undertaken to construct a lateral pilot corrugator and evaluate the resulting combined-board. The project will entail the development of a testing program, the design and construction of a pilot lateral corrugator, and the evaluation of conventional and lateral combined-board samples and boxes.

During the first year of the lateral corrugator design was completed, de-bugged, and experiments conducted to explore the unique heat transfer opportunities of the lateral corrugator. The design of the lateral corrugator proceeded as a retrofit to the pilot scale corrugating line at the IPST Industrial Engineering Center (Fig. 4). The design incorporates a unique glue applicator system to allow the use of high solids adhesives and eliminates single-face festoons from the corrugating process. Both of these unique design features will reduce the energy requirements to produce combined-board. The heat transfer experiments aided in the selection of the post-heating elements to be used for the lateral corrugator. 


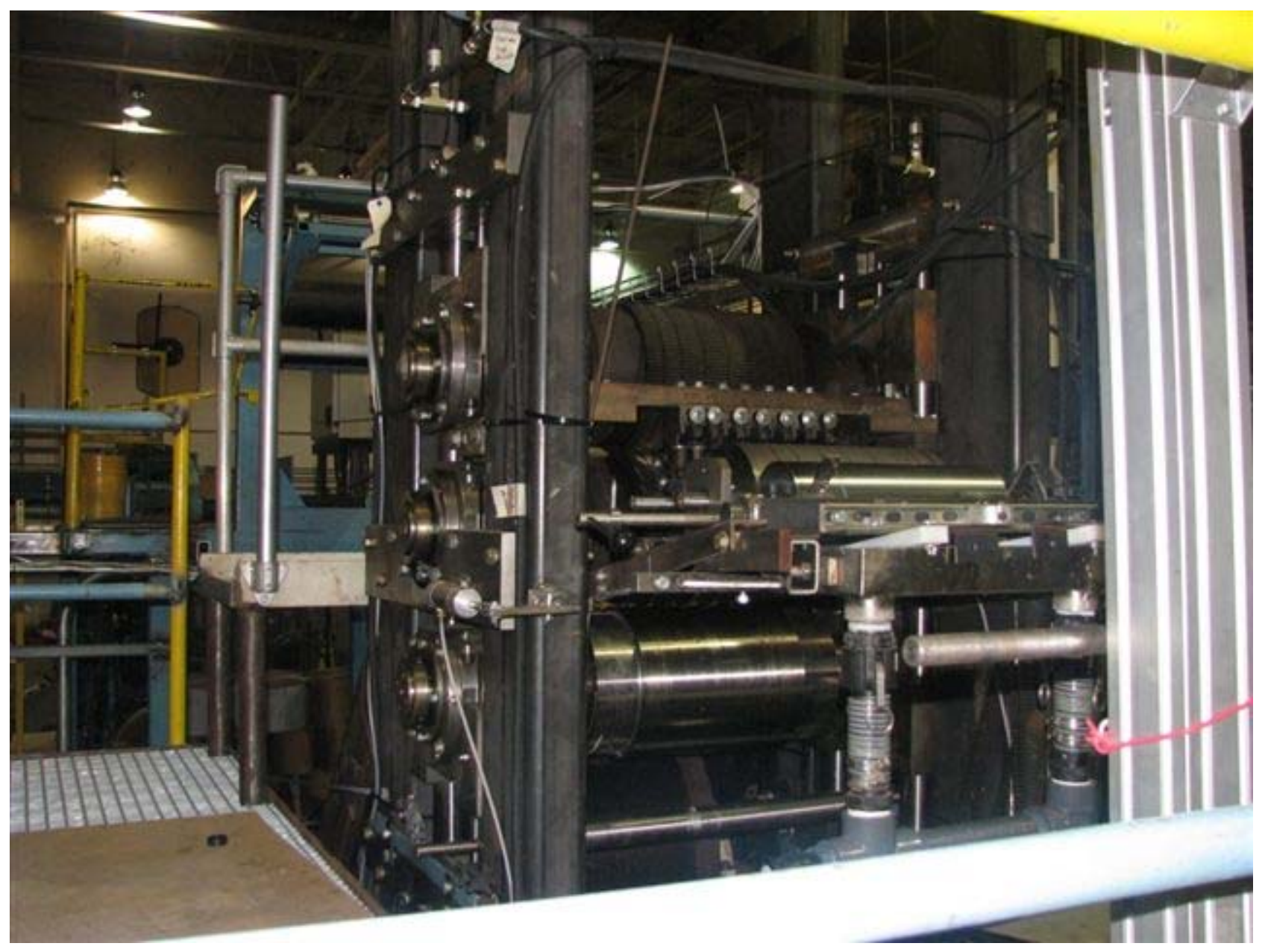

Fig. 4 Photo of new corrugating stack for the pilot lateral corrugator

The second year of the program focused on the fabrication and installation of the corrugating roll stack, the lateral corrugator drive system, the hydraulic and steam supply systems, and the glue machines. Also during the second year of the program the advantages of cut-to-width sheeting associated with lateral corrugator operation were investigated. Cut-to-width sheeting will reduce trim waste at the paper mill and box plant and simplify paper roll management. Since with lateral corrugating the paper is sheeted, matching paper-roll widths at the box plant would not be necessary and corrugator trim waste could likely be controlled. For paper companies, the advantage of the lateral corrugator may be attractive since it would allow papermakers to reduce waste. With the cut-to-width capability of the lateral corrugator, paper companies could produce paper-roll widths to fully trim out paper machines.

The final stage of work involved the design and integration of a gluing system and sheet feeder into the lateral corrugator. The final result was a demonstration run on July 1, 2008 at the pilot facility which produced lateral corrugated combined-board blanks of sufficient size to manufacture small boxes. 


\section{Project Status / Completion:}

Michael Schaepe left the full-time employ of IPST @ Georgia Tech during the fourth quarter, 2007. He worked as a part-time employee until June 30, 2008, at which time the machine was ready for the demonstration run (July 1, 2008). Dr. Frank Murray and Dr. David Orloff assisted during the completion phase of this project. Dr. Roman Popil completed the testing of the board blanks made during the demonstration run.

During the project's final six months, gluing, web guiding and a sheet-feeding mechanisms were designed, built, installed, and de-bugged. The drive / sheet tensioning scheme was developed, and the lateral corrugator (with full steam heat) was run at $100 \mathrm{fpm}$. This completed the July 1, $2008 \mathrm{DOE}$ demonstration run of the complete lateral corrugating equipment. Testing the manually constructed boxes (Fig. 5) produced from blanks made on July 1, 2008 show the improved strength and stiffness properties due to the lateral corrugation technique.

Tri-Star Packaging, which is interested for commercial application of the lateral corrugator concept. Currently a manual insertion of a rotated blank is employed to simulate (and achieve the strength benefit) lateral corrugting is being done at a corrugating facility in Tennessee. The plant produces bulk boxes (triple wall corrugated structures to generate greater strength per unit weight). The integration of the lateral corrugator into a bulk box line is perhaps the best first application of the technology since corrugating speeds for bulk containers falls at the lower end of the production scale, and heavier weight material generates a disproportionately greater strength improvement over lighter weight materials. Specimens of triple wall construction with a rotated middle liner have been built at IPST for testing, which show improved strength results.

The focus of the work at IPST @ GaTech has been largely to determine the impact of lateral corrugating on single-wall structures and box performance. The machinery associated with this project is planned to be re-located as a singular unit to KOHLER COATING, a company in Ohio serving the corrugated box manufacturing community, where it will be available for further research and development work.

\section{Test Results: Analysis of Samples Produces on the July 1, 2008 Demonstration Run}

Test box blanks (Fig 4) were prepared using boards made at the July 12008 demonstration trial. Boards are cut to width and length and flaps scored using a Langston slitter-scorer. Flaps are glued using a conventional wax/EVA hot melt and the manufacturer's joint adhered with cold set PVA. Test box dimensions were $\mathrm{L} \times \mathrm{W} \times \mathrm{H}$ : $14 \times 8 \times 8$ inches and tested for stacking compression strength according to TAPPI method 806 using an Emerson Model 7200 compression tester. 


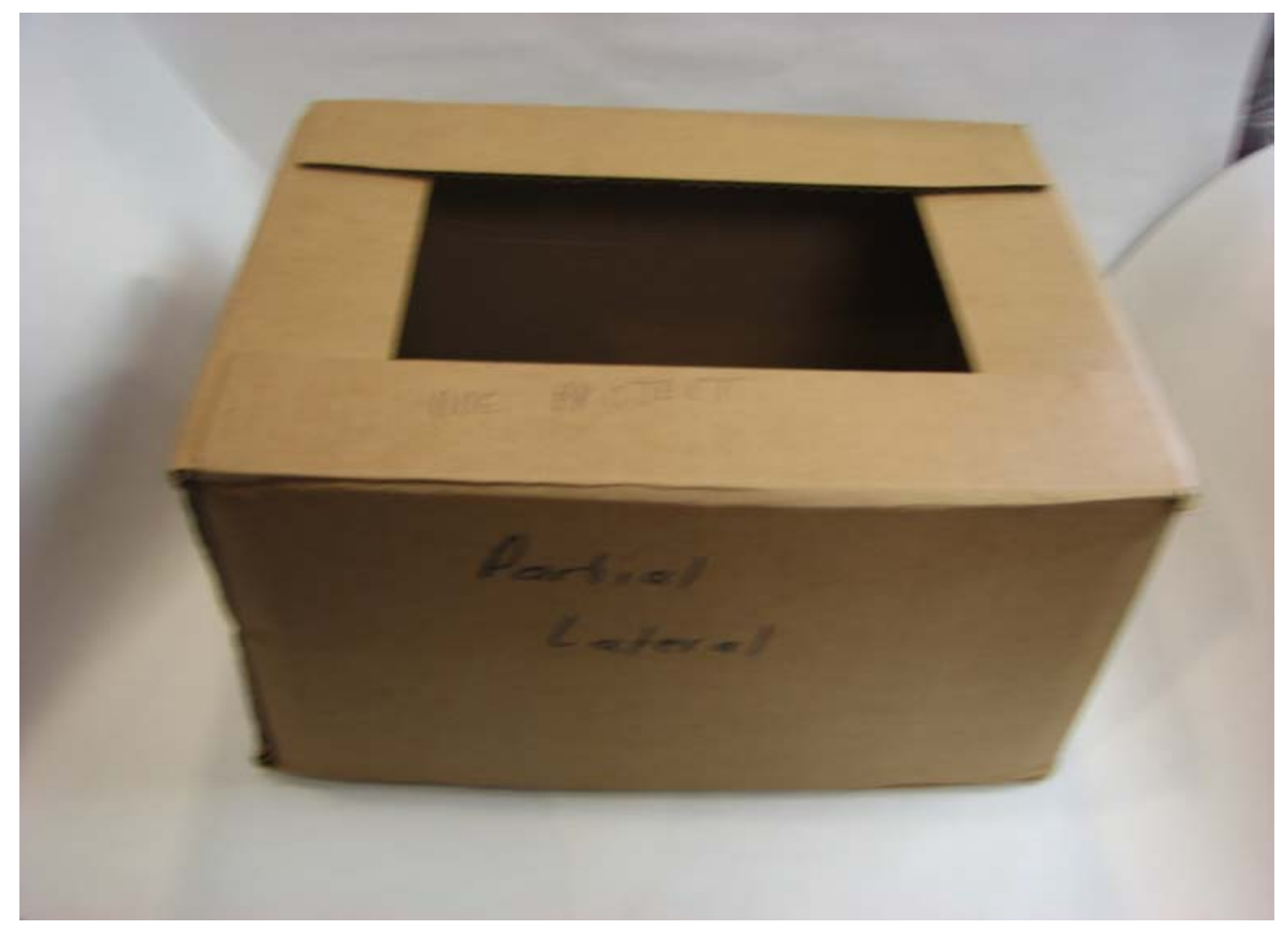

Fig. 5 Photo of box crush test specimen from the DOE demonstration (July 1, 2008)

Samples made available were "Partial Lateral" where the medium and double face linerboard are oriented with the fibers aligned in the perpendicularly to the loading direction as per usual manufacturing practice and "Full Lateral". Sample "Full Lateral" has both single and double facings of the single wall corrugated board rotated such that the fiber orientation is in the direction of vertical loading i.e., rotated 90 degrees compared to customary manufacturing practice.

Table 1 Summary of testing results for samples from the 7/1/08 lateral corrugating demonstration trial

\begin{tabular}{|c|c|c|c|c|}
\hline Sample & \multicolumn{1}{|l|}{ BCT } & Conf. Int. & Deflection & Conf.Int. \\
\hline & $\mathbf{N}$ & $\mathbf{N}$ & $\mathbf{m m}$ & $\mathbf{m m}$ \\
\hline \hline Full & 4730 & 151 & 6.9 & 1.7 \\
\hline Partial & 3874 & 209 & 17.0 & 4.1 \\
\hline
\end{tabular}

The results from the compression testing from test boxes are shown in Table 1. Rotation of both facings ("Full Lateral") results in a compression strength increase of $22 \%$. An earlier previous trial using similar materials and manually spliced linerboard combined on the IPST Langston single facer and manually double backed demonstrated an increase of $12 \%$ between full and partial lateral samples, and an overall increase of $23 \%$ compared to a conventionally oriented test box. This result from the demonstration run is fully consistent with the physical property benefits seen in earlier manual operations. The smaller vertical deflection to failure observed for the "Full Lateral" sample is consistent with a comparative increase in bending stiffness of the rotated component board which in turn causes the failure mode to be increasingly more compressive with reduced panel buckling. 


\section{Savings Dimensional Estimates *:}

Using a conservative basis weight (fiber reduction) savings of $15 \%$ for a Full Lateral box construction versus a Conventional box construction, yields a calculated potential savings to the US liner board producing and corrugated box industry having dimensions exceeding one billion US Dollars (\$1,000,000,000 USD).

Estimated savings based on avoided liner board manufacturing costs:

a) 30 million tons of liner per year (US total) X $15 \%$ reduction $=4.5$ million tons "not made"

b) $4,500,000$ tons @ $\$ 250.00 /$ ton production cost $=\$ 1,125,000,000.00$ avoided cost

Estimated avoided drying energy (@ \$ 6.50/MMBTU and $100 \%$ efficient drying):

a) 30 million tons of liner per year $X 15 \%$ reduction $=4.5$ million tons "not made"

b) 4,500,000 tons of "not dried" liner $=>6,750,000$ tons $\mathrm{H}_{2} \mathrm{O}$ "not evaporated"

c) $6,750,000$ tons $=13,500,000,000$ lbs. $\mathrm{H}_{2} \mathrm{O}$ "not evaporated"

d) $13,500,000,000 \times 970 \mathrm{BTU} / \mathrm{lb}$ (heat of vaporization) $=13,095,000 \mathrm{MMBTU}$

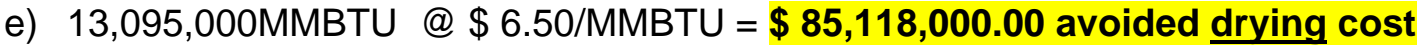

Estimated total avoided energy cost in linerboard manufacturing:

a) 30 million tons of liner per year $\times 15 \%$ reduction $=4.5$ million tons "not made"

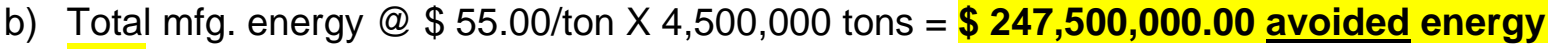
cost

Other potential energy saving benefits from a box making conversion to lateral corrugation include potential transportation fuel savings from lighter weight linerboard roll and resulting boxes, shorter web runs in a newly designed lateral corrugating process which may reduce web pre-heat energy, and potentially lower recycling cost for lighter weight boxes. These energy savings are highly dependent on specific circumstances, and therefore, difficult to meaningfully quantify.

* Input data from Forest Products Journal, Vol. 57, No. 12, Jan/Feb, 2007, "U.S. South linerboard industry: Restoring the competitive edge" by Jacek P. Siry, et. al. 


\section{Publications:}

Previous quarterly project progress reports to DOE were distributed to selected IPST member companies and project commercial partners.

\section{Milestone Status Table:}

\begin{tabular}{|c|c|c|c|c|}
\hline $\begin{array}{l}\text { ID } \\
\text { Number }\end{array}$ & Task / Milestone Description & $\begin{array}{l}\text { Planned } \\
\text { Completion }\end{array}$ & $\begin{array}{c}\text { Actual } \\
\text { Completion }\end{array}$ & Comments \\
\hline 1 & Heat Transfer Experiments & June 2004 & June 2004 & \\
\hline 2 & Splicer and Seam Analysis & June 2004 & June 2004 & \\
\hline 3 & $\begin{array}{l}\text { Address Economic and } \\
\text { Production Considerations }\end{array}$ & Sept 2004 & Sept 2004 & \\
\hline 4 & $\begin{array}{l}\text { Identify Commercialization } \\
\text { Partner }\end{array}$ & Dec 2004 & & Ongoing \\
\hline 5 & Design Lateral Corrugator & July 2005 & July 2005 & \\
\hline 6 & Build Lateral Corrugator & & & \\
\hline $6 a$ & Roll Stack & Dec 2005 & Dec 2005 & \\
\hline $6 \mathrm{~b}$ & $\begin{array}{l}\text { Drive and Steam Supply } \\
\text { Systems }\end{array}$ & Jan 2006 & June 2007 & \\
\hline $6 c$ & Hydraulics & Jan 2006 & & $\begin{array}{l}\text { Electrical connection and } \\
\text { controller programming } \\
\text { completed }\end{array}$ \\
\hline $6 d$ & Glue Machines & Oct 2006 & $\begin{array}{l}\text { Dec 12, } \\
2007\end{array}$ & $\begin{array}{l}\text { Manufacturing } \\
\text { Installation and de-bug }\end{array}$ \\
\hline 7 & $\begin{array}{l}\text { Demonstrate Lateral } \\
\text { Corrugator (i.e., test roll } \\
\text { stack configuration) }\end{array}$ & Nov 2006 & $\begin{array}{l}\text { Nov 21, } \\
2007\end{array}$ & \\
\hline 8 & Design Sheeter & Feb 2007 & $\begin{array}{l}\text { January, } \\
2008\end{array}$ & \\
\hline 9 & Build and Integrate Sheeter & Sept 2007 & April, 2008 & \\
\hline 10 & $\begin{array}{l}\text { Conduct Testing and } \\
\text { Demonstrate Overall } \\
\text { Concept }\end{array}$ & Dec 2007 & July 1, 2008 & $\begin{array}{l}\text { DOE representatives } \\
\text { present, video CD } \\
\text { submitted to DOE }\end{array}$ \\
\hline 11 & Final Report & Dec 2007 & Dec, 2008 & \\
\hline
\end{tabular}




\section{DOE HQ Selected Milestones:}

\begin{tabular}{|l|l|l|}
\hline \multicolumn{1}{|c|}{ Recipient } & CID & \\
\hline \multirow{3}{*}{ Georgia Tech Research Corporation } & \multirow{2}{*}{ DE- FC36 - 01GO 10616} & Milestones \\
\cline { 3 - 4 } & & Attend annual project review with industry \\
\cline { 3 - 4 } & & Complete design of lateral corrugator \\
\cline { 3 - 4 } & & Complete testing of lateral corrugator and demonstrate overall concept. \\
\hline
\end{tabular}

1) Attend annual project review with industry (2004):

Michael Schaepe, "Lateral Corrugator", Agenda 2020 Technology Summit II, Peachtree City, GA, March 28-31, 2004

Michael Schaepe, "Lateral Corrugator: An Improved Method of Manufacturing Corrugated Boxes", Session 32-3, TAPPI Paper Summit, Atlanta, GA, May 3-5, 2004

Michael Schaepe, "An Improved Method of Manufacturing Corrugated Boxes", Program Management Group Meeting, Institute of Paper Science and Technology, Atlanta, GA, May 17,2004

Michael Schaepe, "An Improved Method of Manufacturing Corrugated Boxes: The Lateral Corrugator", Elective Research Consortium Meeting, Institute of Paper Science and Technology, Atlanta, GA, May 19, 2004

Michael Schaepe, "Annual Project Report: An Improved Method of Manufacturing Corrugated Boxes", Institute of Paper Science and Technology, Atlanta, GA, August 10, 2004

Michael Schaepe, "An Improved Method of Manufacturing Corrugated Boxes: The Lateral Corrugator", Poster Session, Forest Products Techno-Business Forum, Institute of Paper Science and Technology and the Center for Paper Business and Institute Studies, Atlanta, GA, October 26-27, 2004

Michael Schaepe, "An Improved Method of Manufacturing Corrugated Boxes: The Lateral Corrugator", Poster Session and Facilities Tour, TAPPI International Corrugated Packaging Conference, Atlanta, GA, November 11, 2004

2) Attend annual project review with industry (2006):

Forest Products Subprogram biannual Peer Review, Atlanta, GA, April 4-6th, 2006; a PowerPoint presentation and poster were presented

Lateral corrugator, one program highlighted in the DOE's Energy Efficiency and Renewable Energy Publication Technology Solutions: Public-Private Partnerships Transforming Industry, May 15, 2006.

Lateral corrugator project added to the DOE's commercialization tracking list

Lateral corrugator project included in the DOE Energy Efficiency and Renewable Energy Industrial Technologies Program publication

3) Complete design of lateral corrugator -

Lateral corrugator design completed July 2005

Lateral corrugator glue machine design completed March 2006 and installed Dec 12, 2007

4) Complete testing of lateral corrugator and demonstrate overall concept - July 1, 2008 


\section{Budget Data:}

Separate submission for Project Completion / Close-out 